\title{
An analytical model for deformation analysis of wind turbine adaptive blades
}

\author{
H. Zhang, A. Maheri, A. Daadbin \& P. Hackney \\ School of Computing, Engineering and Information Sciences, \\ Northumbria University, Newcastle upon Tyne, UK
}

\begin{abstract}
An analytical model capable of predicting the induced deformation due to the presence of bend-twist and stretch-twist elastic couplings in multi-cell closed thin walled beams with arbitrary cross-sections is presented. For various structural and material configurations, the results obtained by the developed model are compared with the results of the finite element analysis. It is shown that the developed analytical model provides reasonable accuracy in predicting induced twist. The developed model is implemented in an aero-structure simulation environment for simulation of wind turbines utilising adaptive blades. Keywords: thin-walled beam, multi-cell closed thin walled beams, adaptive blades, elastic coupling, bending-twist coupling, wind turbine composite blade.
\end{abstract}

\section{Introduction}

Fibrous composite materials have been broadly used in aeronautical and aerospace structures due to their proven advantages, such as high strength-weight ratios. One particular application of these materials is in fabricating smart and adaptive aerodynamic lifting surfaces such as wind turbine adaptive blades and aircraft smart wings. An adaptive blade acts as an open-loop controller that senses the wind velocity or rotor speed variations and adjusts its aerodynamic characteristics accordingly to improve the wind turbine performance. This selfcontrol system can be achieved by implementing elastic coupling in the structure of the blade. In order to determine the aerodynamic performance of adaptive blades at various loading conditions, a structural analyser is required to calculate the induced deformation of the blade. Figure 1 shows the simulation environment for wind turbines utilising this type of blades. Torsional 
deformation of an adaptive blade is the key parameter influencing the wind turbine aerodynamic performance. The accuracy of the predicted torsional deformation is crucial in simulation and design of adaptive blades [1, 2]. A number of analytical models of anisotropic thin-walled beams have been proposed for box beams. Most of researchers employed strain energy and virtual work methods to study the static and dynamic characteristic of thin- and thickwalled beams. Chandra et al. [3] and Kim and White [4] developed analytical models for circumferentially asymmetric stiffness (CAS) and circumferentially uniform stiffness (CUS) for single-cell box beams. They considered the bending, torsional and extensional loads and included shear and warping effects. Their model was, however, limited to rectangular cross-sections. Wu et al. [5] developed another analytical model for torsional loading without using energy method. Kim and Shin [6] provided exact solutions for twist angle and fibre stresses of thin-walled box beams considering the effects of elastic couplings and restrained warping. Lee and Lee [7], Vo and Lee [8,9] also developed two analytical models for beams under torsional loading based on strain energy method. Librescu and Song [10,11] published a set of theories for thin-walled composite beams applicable to deformation and vibration problems. They produced the governing equations of motion with boundary conditions through Hamiltion's principle. Shadmehri et al. [12] developed the static and dynamic characteristics of composite thin-walled beams using non classical effects, such as transverse shear, warping inhibition, non-uniform torsional model and rotary inertia.

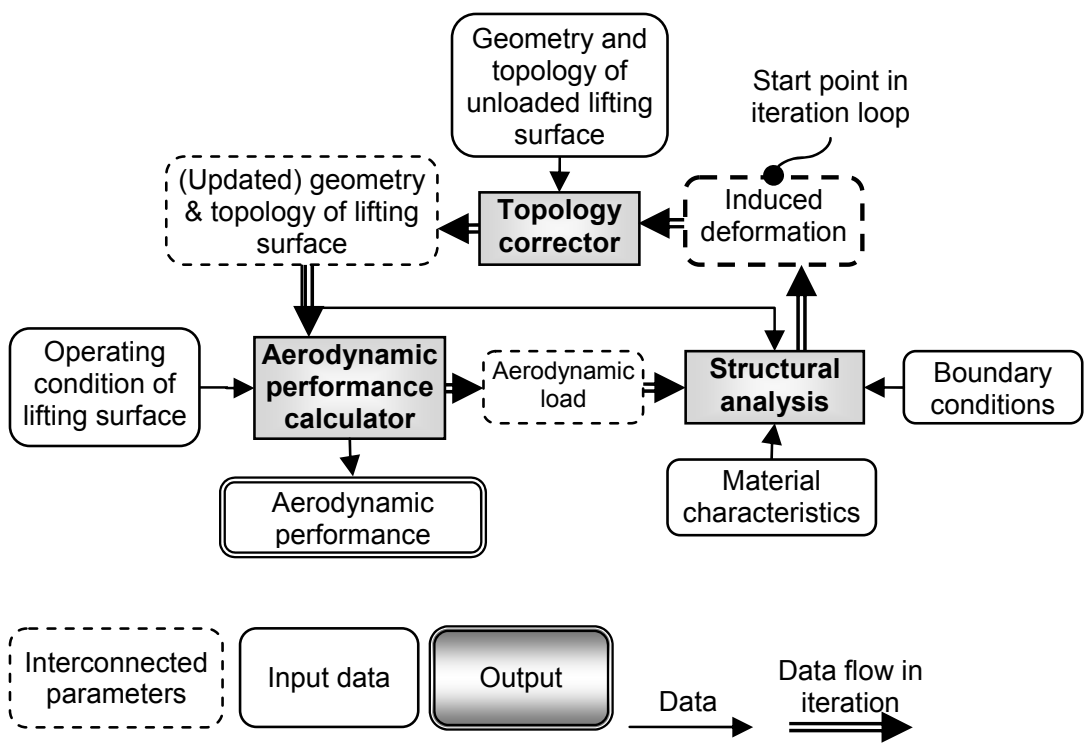

Figure 1: Coupled aero-structure analysis of unbalanced composite lifting surface. 
In view of the deficiencies in the current analytical models, Maheri et al. [1] and Maheri [2] used a robust finite element suite to calculate the deformation in each aerodynamic-structural analysis iteration (Structural Analysis box in Figure 1). In the present study, an efficient and accurate analytical model is developed and employed as the structural analyser.

\section{Analytical model}

The proposed analytical model considers the transverse shear effects and primary warping inhibition. The cross section can have a general shape with up to two webs (three cells). In developing the model, the following basic, still realistic, assumptions are made [10]:

a) The shape of the cross-section and its geometrical dimensions remain invariant in its plane; however deformation normal to the sectional plane are permitted.

b) The transverse shear strain is uniform over the beam.

c) Thin-walled beams are considered only.

The transformed three-dimensional constitutive equations for a generally orthotropic elastic material can be expressed as in Equation (1) [13]:

$$
\left\{\begin{array}{c}
\sigma_{s s} \\
\sigma_{z z} \\
\sigma_{n n} \\
\tau_{z n} \\
\tau_{n s} \\
\tau_{z s}
\end{array}\right\}=\left[\begin{array}{cccccc}
\bar{C}_{11} & \bar{C}_{12} & \bar{C}_{13} & 0 & 0 & \bar{C}_{16} \\
\bar{C}_{12} & \bar{C}_{22} & \bar{C}_{23} & 0 & 0 & \bar{C}_{26} \\
\bar{C}_{13} & \bar{C}_{23} & \bar{C}_{33} & 0 & 0 & \bar{C}_{36} \\
0 & 0 & 0 & \bar{C}_{44} & \bar{C}_{45} & 0 \\
0 & 0 & 0 & \bar{C}_{45} & \bar{C}_{55} & 0 \\
\bar{C}_{16} & \bar{C}_{26} & \bar{C}_{36} & 0 & 0 & \bar{C}_{66}
\end{array}\right]\left\{\begin{array}{c}
\varepsilon_{s s} \\
\varepsilon_{z z} \\
\varepsilon_{\mathrm{nn}} \\
\gamma_{z n} \\
\gamma_{n s} \\
\gamma_{s z}
\end{array}\right\}
$$

Referring to the basic assumptions above, the stresses $\sigma_{s s}, \sigma_{n n}$ and $\tau_{n s}$ can be neglected $\left(\sigma_{s s}=\sigma_{n n}=\tau_{n s}=0\right)$. Rearranging the constitutive equations the reduced constitutive equation for the $k^{\text {th }}$ layer is determined:

where

$$
\left\{\begin{array}{l}
\sigma_{z z} \\
\tau_{z s} \\
\tau_{z n}
\end{array}\right\}_{k}=\left[\begin{array}{ccc}
\widetilde{C}_{11} & \widetilde{C}_{12} & 0 \\
\widetilde{C}_{12} & \widetilde{C}_{22} & 0 \\
0 & 0 & \widetilde{C}_{33}
\end{array}\right]_{k}\left\{\begin{array}{l}
\varepsilon_{z z} \\
\gamma_{z s} \\
\gamma_{z n}
\end{array}\right\}_{k}
$$

$$
\begin{gathered}
\widetilde{C}_{11}=\overline{\mathrm{C}}_{22}+\left(\overline{\mathrm{C}}_{23}^{2} \overline{\mathrm{C}}_{11}+\overline{\mathrm{C}}_{12}^{2} \overline{\mathrm{C}}_{33}-2 \overline{\mathrm{C}}_{13} \overline{\mathrm{C}}_{12} \overline{\mathrm{C}}_{23}\right) /\left(\overline{\mathrm{C}}_{13}^{2}-\overline{\mathrm{C}}_{33} \overline{\mathrm{C}}_{11}\right) \\
\widetilde{C}_{12}=\overline{\mathrm{C}}_{26}+\left(-\overline{\mathrm{C}}_{12} \overline{\mathrm{C}}_{13} \overline{\mathrm{C}}_{36}+\overline{\mathrm{C}}_{12} \overline{\mathrm{C}}_{16} \overline{\mathrm{C}}_{33}-\overline{\mathrm{C}}_{16} \overline{\mathrm{C}}_{23} \overline{\mathrm{C}}_{13}+\overline{\mathrm{C}}_{11} \overline{\mathrm{C}}_{36} \overline{\mathrm{C}}_{23}\right) /\left(\overline{\mathrm{C}}_{13}^{2}-\overline{\mathrm{C}}_{33} \overline{\mathrm{C}}_{11}\right) \\
\widetilde{C}_{21}=\widetilde{\mathrm{C}}_{12} \\
\widetilde{C}_{22}=\overline{\mathrm{C}}_{66}+\left(-\overline{\mathrm{C}}_{16} \overline{\mathrm{C}}_{13} \overline{\mathrm{C}}_{36}+\overline{\mathrm{C}}_{16}^{2} \overline{\mathrm{C}}_{33}+\overline{\mathrm{C}}_{36}^{2} \overline{\mathrm{C}}_{11}-\overline{\mathrm{C}}_{36} \overline{\mathrm{C}}_{16} \overline{\mathrm{C}}_{13}\right) /\left(\overline{\mathrm{C}}_{13}^{2}-\overline{\mathrm{C}}_{33} \overline{\mathrm{C}}_{11}\right) \\
\widetilde{C}_{33}=\overline{\mathrm{C}}_{44}-\overline{\mathrm{C}}_{45}^{2} / \overline{\mathrm{C}}_{55}
\end{gathered}
$$

Figure 2 shows two systems of coordinates used to drive the forcedeformation relations. 


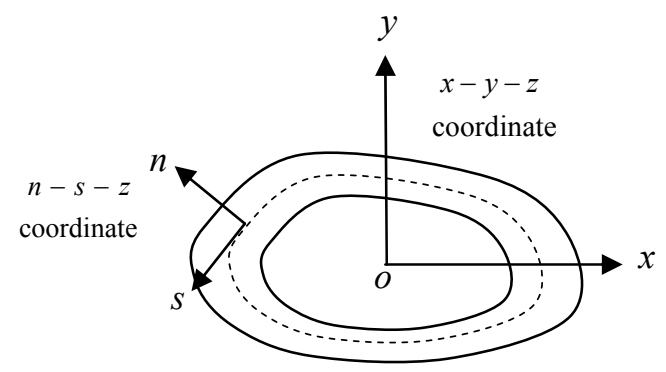

Figure 2: Global and local system of coordinates.

Displacement vector $\{u, v, w\}$ of a general point is given as in Equation (4) [10]:

$$
\begin{gathered}
u(x, y, z, t)=u_{p}(z, t)-\left(y-y_{p}\right) \phi(z, t) \\
v(x, y, z, t)=v_{p}(z, t)+\left(x-x_{p}\right) \phi(z, t) \\
w(s, z, n, t)=w_{0}(z, t)+\theta_{y}(z, t)\left(x+n \frac{d y}{d s}\right)+\theta_{x}(z, t)\left(y-n \frac{d x}{d s}\right) \\
-\phi^{\prime}(z, t) \int_{0}^{s}\left(r_{n}(\bar{s})-\frac{2 \Omega}{h(\bar{s}) G_{s z}(\bar{s}) L}\right) d \bar{s}
\end{gathered}
$$

where $u_{p}$ and $v_{p}$ stand for the $u$ and $v$ displacements of a reference point (here the origin of the $x-y-z$ system of coordinates), $w_{0}$ is the displacement of a reference point on the $n-s-z$ system of coordinate along the z-axis, $\Omega$ is the area inside the centreline of the cross-section, $h$ is the shell thickness, $L=\oint d s / h(s) G_{s z}(s), \phi$ is the rotation about z-axis and $\theta_{x}$ and $\theta_{y}$ are the rotations about the $\mathrm{x}$ and $\mathrm{y}$ axes, given by:

$$
\begin{aligned}
& \theta_{x}(z, t)=\gamma_{y z}-v_{p}^{\prime} \\
& \theta_{y}(z, t)=\gamma_{x z}-u_{p}^{\prime}
\end{aligned}
$$

The strain field in the $n-s-z$ system of coordinate for a single- cell beam can be defined as [10]:

$$
\begin{gathered}
\mathcal{E}_{z z}(s, z, n, t)=w_{0}^{\prime}+\theta_{x}^{\prime}\left(y-n \frac{d x}{d s}\right)+\theta_{y}^{\prime}\left(x+n \frac{d y}{d s}\right) \\
-\phi^{\prime \prime}(z, t)\left\{\int_{0}^{s} r_{n}(\bar{s}) d \bar{s}-\int_{0}^{s} \frac{2 \Omega}{h(\bar{s}) G(\bar{s}) L} d \bar{s}\right\} \\
\Gamma_{s z}(s, z, n, t)=\left[\theta_{y}(z, t)+u_{p}^{\prime}\right] \frac{d x}{d s}+\left[\theta_{x}(z, t)+v_{p}^{\prime}\right] \frac{d y}{d s} \\
+\phi^{\prime}(z, t)\left\{\frac{2 \Omega}{h(s) G(s) L}+\frac{2 n \beta}{h(s) G(s) L}\right\} \\
\Gamma_{n z}(s, z, n, t)=\left[\theta_{y}(z, t)+u_{p}^{\prime}\right] \frac{d y}{d s}-\left[\theta_{x}(z, t)+v_{p}^{\prime}\right] \frac{d x}{d s}
\end{gathered}
$$


In the case of multi-cell cross-sections, the rate of the rotation of the $\mathrm{R}^{\text {th }}$ cell surrounded by m adjacent cells, is given by [10]:

$$
\phi_{R}^{\prime}=\frac{1}{2 \Omega_{R} \widetilde{G}}\left(q_{R} \delta_{R}-\sum_{r=1}^{m} q_{r} \delta_{r, R}\right)
$$

where $\widetilde{G}$ is a conveniently chosen shear modulus (here the average of $G_{s z}$ ), $q$ is the shear flow in the cell, $\Omega_{R}$ is the area enclosed by $R^{\text {th }}$ cell mid-line contour and parameters $\delta_{R}$ and $\delta_{r}$ are defined as: $\delta_{R}=\oint \frac{d s}{\widetilde{h}}$ and $\delta_{r}=\int_{r, R} \frac{d s}{\widetilde{h}}$.

Since the twist angle rate is the same for all connected cells, $\left[\phi^{\prime}\right],[q]$ and $[H]$ can be expressed as:

$$
\begin{gathered}
{\left[\phi^{\prime}\right]=[s][q]} \\
{[q]=[H] \phi^{\prime}}
\end{gathered}
$$

where $[H]=[s]^{-1}[I]$ and $[I]$ is the unit vector. Using Equations (8) through (10), the strain field for thin-walled multi-cell beams can be derived as in Equation (11)

$$
\begin{gathered}
\varepsilon_{z z}(s, z, n, t)=w_{0}^{\prime}+\theta_{x}^{\prime}\left(y-n \frac{d x}{d s}\right)+\theta_{y}^{\prime}\left(x+n \frac{d y}{d s}\right) \\
+\phi^{\prime \prime}(z, t) \int_{0}^{s}\left(\frac{H}{h(\bar{s}) G(\bar{s})}\right) d \bar{s} \\
\Gamma_{s z}(s, z, n, t)=\left[\theta_{y}(z, t)+u_{p}^{\prime}\right] \frac{d x}{d s}+\left[\theta_{x}(z, t)+v_{p}{ }^{\prime}\right] \frac{d y}{d s} \\
+\phi^{\prime}(z, t)\left(\frac{H}{h(s) G(s)}\right) \\
\Gamma_{n z}(s, z, n, t)=\left[\theta_{y}(z, t)+u_{p}^{\prime}\right] \frac{d y}{d s}-\left[\theta_{x}(z, t)+v_{p}^{\prime}\right] \frac{d x}{d s}
\end{gathered}
$$

The generalised resultant forces and moments acting over the cross-section at a span location $\mathrm{z}$ can be related to the stresses in the beam by employing the equilibrium equations in the global system of coordinates:

$$
\begin{aligned}
& F(z)=\iint_{z z} d s d n \\
& V_{x}(z)=\iint \tau_{z s} \overrightarrow{e_{s}} \cdot \vec{i} d s d n+\iint \tau_{z n} \overrightarrow{e_{n}} \cdot \vec{i} d s d n \\
& V_{y}(z)=\iint \tau_{z s} \overrightarrow{e_{s}} \cdot \vec{j} d s d n+\iint \tau_{z n} \overrightarrow{e_{n}} \cdot \vec{j} d s d n \\
& M_{x}(z)=\iint_{z z}(y-n d x / d s) d s d n \\
& M_{y}(z)=-\iint_{z z}(x+n d y / d s) d s d n \\
& T(z)=\iint_{-}-\left(\tau_{z s} \vec{e}_{t} \cdot \vec{i}+\tau_{z n} \vec{e}_{n} \cdot \vec{i}\right)\left(y-n \frac{d x}{d s}\right) d s d n \\
& +\iint\left(\tau_{z s} \vec{e}_{t} \cdot \vec{j}+\tau_{z n} \vec{e}_{n} \cdot \vec{j}\right)\left(x+n \frac{d y}{d s}\right) d s d
\end{aligned}
$$


where $F(z), V_{x}(z)$ and $V_{y}(z)$ denote the resultant axial and shear forces in the $\mathrm{z}, \mathrm{x}$ and y directions respectively, $M_{x}(z), M_{y}(z)$ and $T(z)$ are the resultant moments about the $\mathrm{x}, \mathrm{y}$ and $\mathrm{z}$ axis, $\vec{i}$ and $\vec{j}$ stand for the unite vectors along the global $\mathrm{x}$ and $\mathrm{y}$ axes and $\vec{e}_{s}$ and $\vec{e}_{\mathrm{n}}$ are the unit vectors along the local $\mathrm{s}$ and $\mathrm{n}$ axes respectively. Neglecting the second order term ( $\left.\phi^{\prime \prime}\right)$ in Equations (7a) and (11a), the forces-displacement relations are obtained as follows:

$$
\left[\begin{array}{c}
F(z) \\
V_{x}(z) \\
V_{y}(z) \\
T(x) \\
M_{x}(x) \\
M_{y}(x)
\end{array}\right]=\left[\begin{array}{llllll}
K_{11} & K_{12} & K_{13} & K_{14} & K_{15} & K_{16} \\
K_{21} & K_{22} & K_{23} & K_{24} & K_{25} & K_{26} \\
K_{31} & K_{32} & K_{33} & K_{34} & K_{35} & K_{36} \\
K_{41} & K_{42} & K_{43} & K_{44} & K_{45} & K_{46} \\
K_{51} & K_{52} & K_{53} & K_{54} & K_{55} & K_{56} \\
K_{61} & K_{62} & K_{63} & K_{64} & K_{65} & K_{66}
\end{array}\right]\left[\begin{array}{c}
w_{0}^{\prime}(x) \\
\theta_{y}^{\prime}(z) \\
\theta_{x}^{\prime}(z) \\
\theta_{y}+u_{p}^{\prime} \\
\theta_{x}+v_{p}^{\prime} \\
\phi^{\prime}(z)
\end{array}\right]
$$

The entries of the stiffness matrix are given in the appendix.

\section{Validation and numerical results}

To verify the accuracy of the developed analytical model, the blade of a 2-bladed AWT27 wind turbine is chosen for deformation analysis under realistic loading conditions. The blade has a span of $12.57 \mathrm{~m}$ and is constructed of S809 and S814 aerofoils. The external loading is calculated at a wind speed of $10 \mathrm{~m} / \mathrm{s}$ using the aerodynamic code WTAero. Various unbalanced material configurations producing bend-twist elastic coupling, as listed in Tables (1) through (3), are considered for the blade. In all cases the mechanical properties of the composite material (AS4/3501-6 graphite/epoxy) and the shell thickness are the same: total shell thickness $=20 \mathrm{~mm}, E_{11}=141.96 \mathrm{GPa}, E_{22}=E_{33}=9.79 \mathrm{GPa}, G_{12}=G_{13}=6.0 \mathrm{GPa}$, $G_{23}=4.83 \mathrm{GPa}, v_{12}=v_{13}=0.24$ and $v_{23}=0.5$. The predicted induced twist angle is compared with the results of finite element analysis (FEA) using ANSYS software with SHELL99 element. Results are shown in Figures 3-5.

Table 1: $\quad$ Configurations without web.

\begin{tabular}{|c|c|c|c|}
\hline Layup configurations & Top surface & Lower surface & Web \\
\hline 1 & {$[20]_{20}$} & {$[-20]_{20}$} & No \\
\hline 2 & {$[30]_{20}$} & {$[-30]_{20}$} & No \\
\hline 3 & {$[40]_{20}$} & {$[-40]_{20}$} & No \\
\hline 4 & {$[50]_{20}$} & {$[-50]_{20}$} & No \\
\hline
\end{tabular}

Table 2: $\quad$ Configurations with one web.

\begin{tabular}{|c|c|c|c|}
\hline Layup configurations & Top surface & Lower surface & Web \\
\hline 5 & {$[20]_{20}$} & {$[-20]_{20}$} & {$[45 /-45]_{10}$} \\
\hline 6 & {$[30]_{20}$} & {$[-30]_{20}$} & {$[45 /-45]_{10}$} \\
\hline 7 & {$[40]_{20}$} & {$[-40]_{20}$} & {$[45 /-45]_{10}$} \\
\hline 8 & {$[50]_{20}$} & {$[-50]_{20}$} & {$[45 /-45]_{10}$} \\
\hline
\end{tabular}


Table 3: $\quad$ Configurations with two webs.

\begin{tabular}{|c|c|c|c|c|}
\hline Layup configurations & Top surface & Lower surface & Web 1 & Web 2 \\
\hline 9 & {$[20]_{20}$} & {$[-20]_{20}$} & {$[45 /-45]_{10}$} & {$[45 /-45]_{10}$} \\
\hline 10 & {$[30]_{20}$} & {$[-30]_{20}$} & {$[45 /-45]_{10}$} & {$[45 /-45]_{10}$} \\
\hline 11 & {$[40]_{20}$} & {$[-40]_{20}$} & {$[45 /-45]_{10}$} & {$[45 /-45]_{10}$} \\
\hline 12 & {$[50]_{20}$} & {$[-50]_{20}$} & {$[45 /-45]_{10}$} & {$[45 /-45]_{10}$} \\
\hline
\end{tabular}

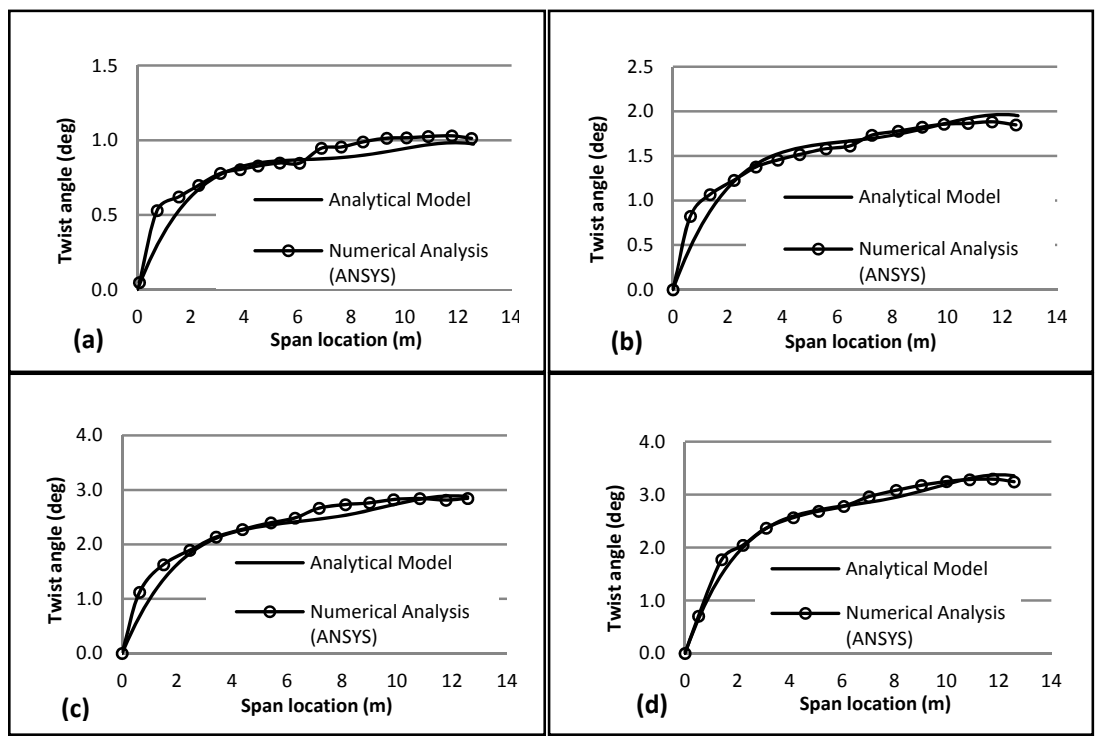

Figure 3: Twist angle (a) configuration 1, (b) configuration 2, (c) configuration 3, and (d) configuration 4.

As it can be observed from these figures, the predicted twist using the developed analytical model is in good agreement with the results of FEA for most of the configurations. The maximum differences between the analytical and numerical results correspond to the one- and two-web configurations with a ply angle of 20 degrees. In these two cases the overall twist angle is very small (below 1 degree). Cases like these do not have any practical applications in adaptive blades. In all cases, a large deviation between the analytical and numerical results can be observed in span locations close to the root of the blade. This is due to the fact that the developed analytical model ignores the torsional restrained at the fixed end of the blade. It should be noted that since the inner parts of the blades have minor effects on the overall aerodynamic performance of wind turbines, this deviation has negligible effect on the predicted aerodynamic performance of the unit.

\section{Analytical model in practice}

In this section, the performance of the analytical model is shown by carrying out a coupled aero-structure simulation of a wind turbine with bend-twist adaptive blades, as illustrated in Figure 1. The rotor aerodynamic code (WTAero) 


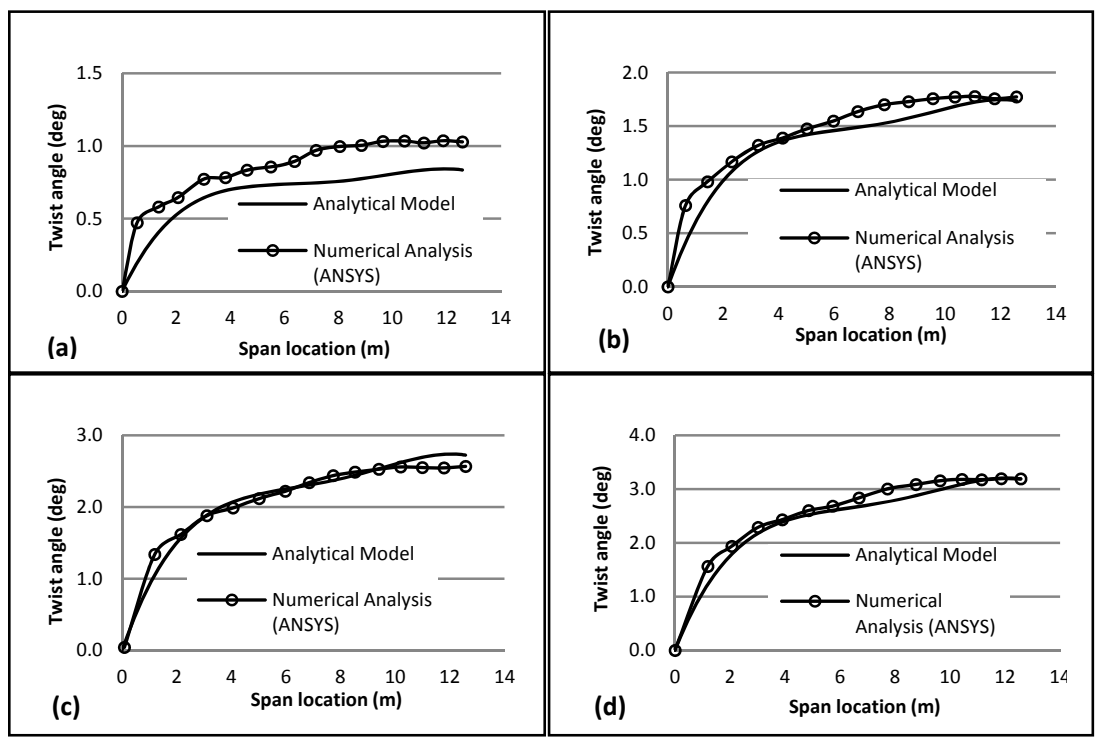

Figure 4: Twist angle (a) configuration 5, (b) configuration 6, (c) configuration 7 , and (d) configuration 8 .

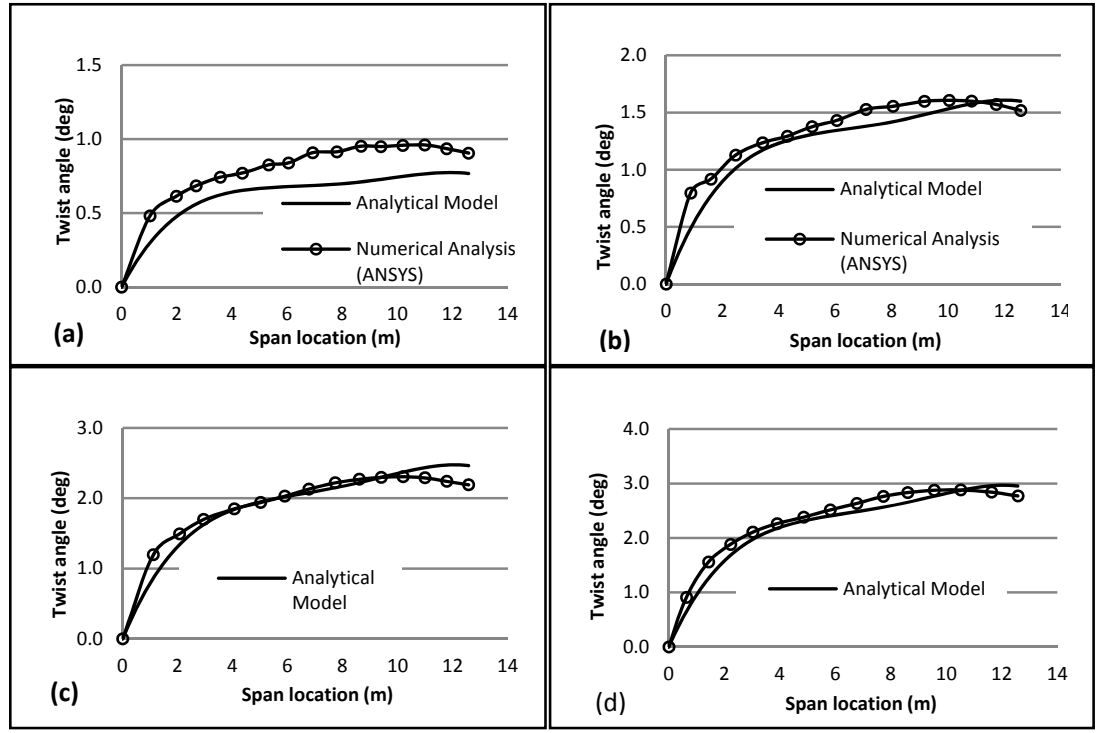

Figure 5: Twist angle (a) Configuration 9, (b) Configuration 10, (c) Configuration 11, and (d) Configuration 12. 


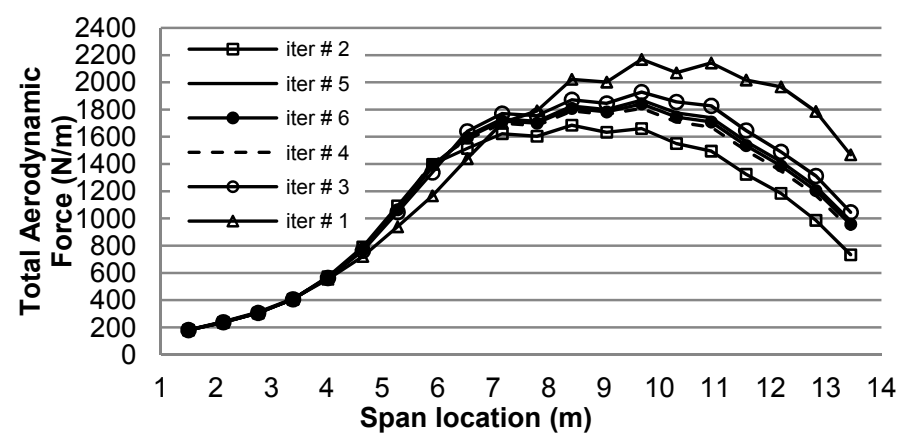

Figure 6: $\quad$ Span-wise distribution of total aerodynamic force.

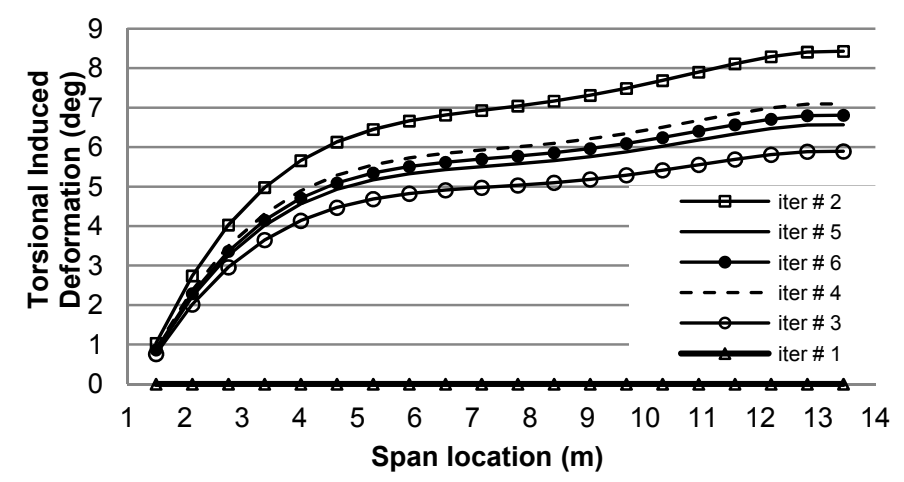

Figure 7: Span-wise distribution of the torsional-induced deformation.

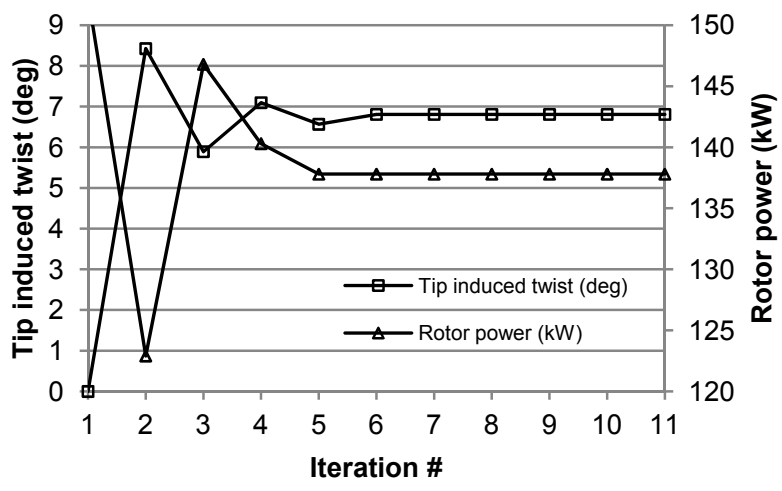

Figure 8: Aerodynamic performance of the wind turbine utilising adaptive blades.

employs the updated blade topology to calculate the aerodynamic load on the blade as well as the rotor mechanical power. The studied adaptive blade has no web and has similar aerofoil, chord and pretwist distributions as those of the 
blades of AWT27 wind turbines but with a different lay-up configuration. The skin of the adaptive blades is made of graphite/epoxy with 50 degrees off-axis mirror layup with a constant thickness of $10 \mathrm{~mm}$. Mechanical properties of the blade skin are as given in Section 3. Running the coupled aero-structure analysis with a zero initial induced twist, it was observed that depending on the wind turbine operating condition, it takes 6-13 iterations to achieve a solution satisfying the convergence criterion of $\left|\left(P_{\text {new }}-P_{\text {old }}\right) / P_{\text {old }}\right| \leq 1 \%$. Figures 6-8 show the results of the first six iterations of coupled aero-structure analysis of this wind turbine operating at a steady wind speed of $10 \mathrm{~m} / \mathrm{s}$ with a rotor speed of $53.3 \mathrm{rpm}$.

\section{Conclusions}

The developed analytical model for deformation analysis of multi-cell thinwalled unbalanced composite beams can be employed for predicting the induced twist in adaptive blades with required accuracy. The advantages of this model lie in its simplicity, efficiency and providing reasonable accuracy.

\section{Appendix}

Entries of the stiffness matrix in Equation (13):

$$
\begin{aligned}
& K_{n}=\iint \tilde{C}_{\text {"I }}^{\prime} d n d s \\
& K_{\mathrm{r}}=\iint \tilde{C}_{\mathrm{in}}^{\prime}\left(x+n \frac{d y}{d s}\right) d n d s \\
& K_{\mathrm{n}}=\iint \tilde{C}_{\mathrm{in}}^{\prime}\left(y-n \frac{d x}{d s}\right) d n d s \\
& K_{14}=\iint \tilde{C}_{12}^{\prime} \frac{d x}{d s} d n d s \\
& K_{1 s}=\iint \tilde{C}_{12} \frac{d y}{d s} d n d s \\
& K_{\mathrm{lb}}=\iint \tilde{C}_{12}^{\prime}\left(\frac{2 \Omega+2 n \beta}{h(s) G_{s}(s) L}\right) d n d s
\end{aligned}
$$

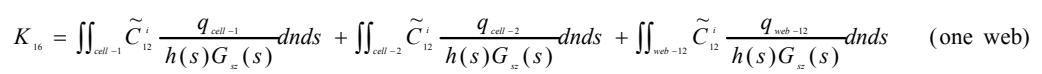

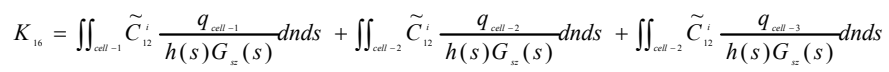

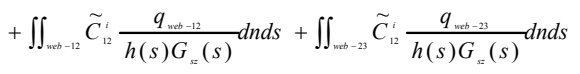

$$
\begin{aligned}
& \text { (no web) } \\
& \text { (two webs) }
\end{aligned}
$$




$$
\begin{aligned}
& K_{21}=\iint \tilde{C}_{12}^{i} \frac{d x}{d s} d n d s \\
& K_{22}=\iint \widetilde{C}_{12}^{i}\left(x+n \frac{d y}{d s}\right) \frac{d x}{d s} d n d s \\
& K_{23}=\iint \tilde{C}_{12}^{i}\left(y-n \frac{d x}{d s}\right) \frac{d x}{d s} d n d s \\
& K_{24}=\iint\left(\tilde{C}_{22}^{i}\left(\frac{d x}{d s}\right)^{2}+\tilde{C}_{33}^{i}\left(\frac{d y}{d s}\right)^{2}\right) d n d s \\
& K_{25}=\iint\left(\tilde{C}_{22}^{i} \frac{d x}{d s} \frac{d y}{d s}-\tilde{C}_{33}^{i} \frac{d x}{d s} \frac{d y}{d s}\right) d n d s \\
& K_{26}=\iint \tilde{C}_{22}^{i}\left(\frac{2 \Omega+2 n \beta}{h(s) G_{v}(s) L}\right) \frac{d x}{d s} d n d s
\end{aligned}
$$

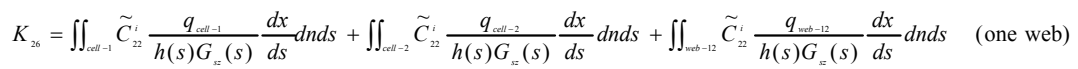

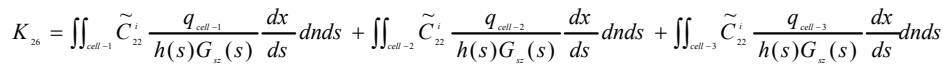

$$
\begin{aligned}
& +\iint_{w e c h-12} \tilde{C}_{22}^{i} \frac{q_{w w h-12}}{h(s) G_{s z}(s)} \frac{d x}{d s} d n d s+\iint_{w n b-23} \tilde{C}_{22}^{i} \frac{q_{w x b-23}}{h(s) G_{s z}(s)} \frac{d x}{d s} d n d s \\
& \text { (two webs) } \\
& K_{31}=\iint \tilde{C}_{12} \frac{d y}{d s} d n d s \\
& K_{12}=\iint \tilde{C}_{12}^{\prime}\left(x+n \frac{d y}{d s}\right) \frac{d y}{d s} d n d s \\
& K_{33}=\iint \tilde{C}_{12}^{\prime}\left(y-n \frac{d x}{d s}\right) \frac{d y}{d s} d n d s \\
& K_{34}=\iint\left(\tilde{C}_{22}^{i}\left(\frac{d y}{d s} \frac{d x}{d s}\right)-\tilde{C}^{\prime 3}\left(\frac{d y}{d s} \frac{d x}{d s}\right)\right) d n d s \\
& K_{35}=\iint\left(\tilde{C}_{22}^{\prime}\left(\frac{d y}{d s}\right)^{2}+\tilde{C}^{\prime}{ }_{33}\left(\frac{d x}{d s}\right)^{2}\right) d n d s \\
& K_{36}=\iint \tilde{C}_{22}^{\prime}\left(\frac{2 \Omega+2 n \beta}{h(s) G_{s}(s) L}\right) \frac{d y}{d s} d n d s
\end{aligned}
$$

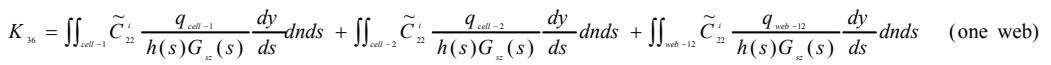

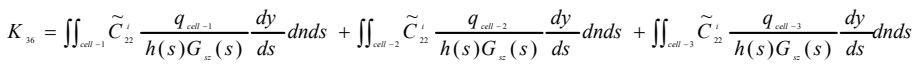

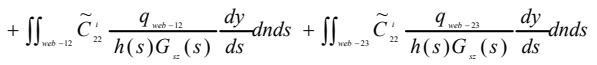

$K_{41}=\iint \tilde{C}_{12}\left(x \frac{d y}{d s}-y \frac{d x}{d s}+n\right) d n d s$

$K_{42}=\iint \tilde{C}_{12}\left(x+n \frac{d y}{d s}\right)\left(x \frac{d y}{d s}-y \frac{d x}{d s}+n\right) d n d s$

$K_{43}=\iint \tilde{C}_{12}\left(y-n \frac{d x}{d s}\right)\left(x \frac{d y}{d s}-y \frac{d x}{d s}+n\right) d n d s$

$K_{44}=\iint\left[\tilde{C}_{22} \frac{d x}{d s}\left(x \frac{d y}{d s}-y \frac{d x}{d s}+n\right)-\tilde{C}_{33} \frac{d y}{d s}\left(x \frac{d x}{d s}+y \frac{d y}{d s}\right)\right] d n d s$

$K_{4 s}=\iint\left[\tilde{C}_{22} \frac{d y}{d s}\left(x \frac{d y}{d s}-y \frac{d x}{d s}+n\right)+\tilde{C}_{33} \frac{d x}{d s}\left(x \frac{d x}{d s}+y \frac{d y}{d s}\right)\right] d n d s$

$K_{46}=\iint \widetilde{C}_{22}\left(\frac{2 \Omega+2 n \beta}{h(s) G_{s=}(s) L}\right)\left(x \frac{d y}{d s}-y \frac{d x}{d s}+n\right) d n d s$

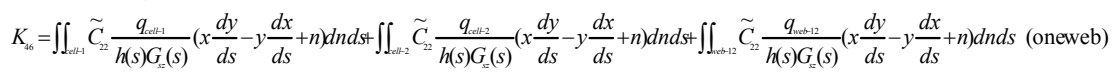

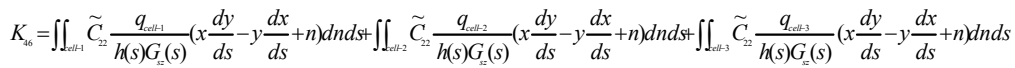

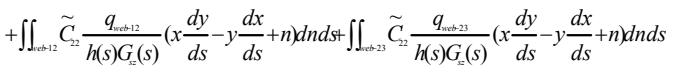




$$
\begin{aligned}
& K_{51}=\iint \tilde{C}_{11}^{i}\left(y-n \frac{d x}{d s}\right) d n d s \\
& K_{52}=\iint \tilde{C}_{11}^{i}\left(x+n \frac{d y}{d s}\right)\left(y-n \frac{d x}{d s}\right) d n d s \\
& K_{53}=\iint \tilde{C}_{11}^{i}\left(y-n \frac{d x}{d s}\right)^{2} d n d s \\
& K_{\mathrm{s4}}=\iint \tilde{C}_{12}^{i} \frac{d x}{d s}\left(y-n \frac{d x}{d s}\right) d n d s \\
& K_{55}=\iint \tilde{C}_{12}^{i} \frac{d y}{d s}\left(y-n \frac{d x}{d s}\right) d n d s \\
& K_{56}=\iint \widetilde{C}_{12}^{i}\left(\frac{2 \Omega+2 n \beta}{h(s) G_{s}(s) L}\right)\left(y-n \frac{d x}{d s}\right) d n d s
\end{aligned}
$$

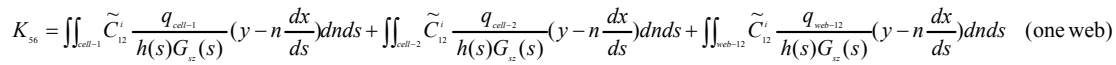

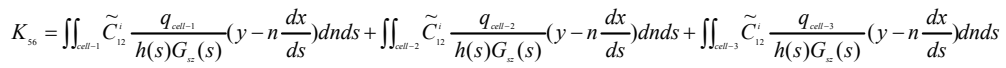

$$
\begin{aligned}
& +\iint_{w b-12} \tilde{C}_{12}^{i} \frac{q_{m s i-12}}{h(s) G_{s}(s)}\left(y-n \frac{d x}{d s}\right) d n d s+\iint_{w a c h-23} \widetilde{C}_{12}^{i} \frac{q_{m b-23}}{h(s) G_{s c}(s)}\left(y-n \frac{d x}{d s}\right) d n d s \\
& \text { (two webs) } \\
& K_{61}=-\iint \tilde{C}_{11}^{i}\left(x+n \frac{d y}{d s}\right) d n d s \\
& K_{62}=-\iint \tilde{C}_{11}^{i}\left(x+n \frac{d y}{d s}\right)^{2} d n d s \\
& K_{63}=-\iint \tilde{C}_{11}^{u}\left(y-n \frac{d x}{d s}\right)\left(x+n \frac{d y}{d s}\right) d n d s \\
& K_{64}=-\iint \tilde{C}_{12} \frac{d x}{d s}\left(x+n \frac{d y}{d s}\right) d n d s \\
& K_{6 s}=-\iint \tilde{C}_{12}^{\prime} \frac{d y}{d s}\left(x+n \frac{d y}{d s}\right) d n d s \\
& K_{66}=-\iint \tilde{C}_{12}^{\prime}\left(\frac{2 \Omega+2 n \beta}{h(s) G_{v s}(s) L}\right)\left(x+n \frac{d y}{d s}\right) d n d s \\
& \text { (noweb) }
\end{aligned}
$$

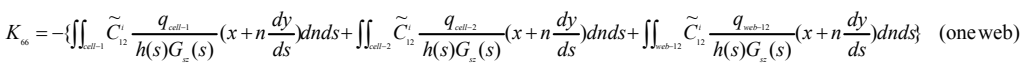

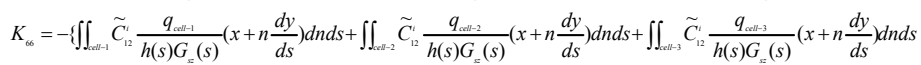

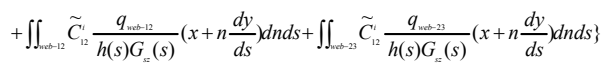

where $\beta$ is the perimeter of centreline of the cross-section.

\section{References}

[1] Maheri, A., Noroozi, S., Toomer, C., and Vinney, J., WTAB, a Computer Program for Predicting the Performance of Horizontal Axis Wind Turbines with Adaptive Blades, Renewable Energy, 31(11), pp 1673-1685, 2006.

[2] Maheri, A., A Finite Element Suite for Deformation Analysis of Composite Aeroelastic Structures Subjected to Operational Aerodynamic Loading, Proc. IMechE-C, Journal of Mechanical Science, 2011, doi: 10.1177/0954406211429763.

[3] Chandra, R., Stemple, A.D. and Chopra, I., Thin-walled composite beams under bending, torsional, and Extensional Loads. Aircraft, 27(47), 1990.

[4] Kim, C. and White, S. R., Thick-walled composite beam theory including 3-d elastic effects and torsional warping. International Journal of Solids and Structures, 34(31-32), pp. 4237-4259, 1997. 
[5] Wu, Y., Zhu, Y., Lai, Y., Zhang, X., and Liu, S., Analysis of thin-walled composite box beam under torsional load without external restraint. ThinWalled Structure, 40, pp. 385-397, 2002.

[6] Kim, N.I. and Shin, D. K., Torsional analysis of thin-walled composite beams with single- and double-celled sections. Engineering Structures, 31(7), pp. 1509-1521, 2009.

[7] Lee, J. and Lee, S.H., Flexural-torsional behavior of thin-walled composite beams. Thin-Walled Structures, 42(9), pp. 1293-1305, 2004.

[8] Vo, T.P. and Lee, J., Flexural-torsional behavior of thin-walled closedsection composite box beams. Engineering Structures, 29(8), pp. 1774$1782,2007$.

[9] Vo, T.P. and Lee, J., Flexural-torsional behavior of thin-walled composite box beams using shear-deformable beam theory. Engineering Structures, 30(7), pp. 1958-1968, 2008.

[10] Librescu, L. and Song O. Thin-walled composite beams theory and application. Berlin, Springer, 2006.

[11] Librescu, L., and Song, O., Behaviour of thin-walled beams made of advanced composite materials and incorporating non-classical effects, Applied Mechanicals Reviews, 44(11), pp. 174-180, 1990.

[12] Shadmehri, F., Haddadpour, H., and Kouchakzadeh, M.A. Flexuraltorsional behaviour of thin-walled composite beams with closed crosssection. Thin-Walled Structures, 45(7-8), pp. 699-705, 2007.

[13] Bertholet, J.M., Composite materials: mechanical behaviour and structural analysis, New York, Springer, 1999. 